\title{
ELECTRICAL AND CAPACITANCE DIAGNOSTIC TECHNIQUES AS A SUPPORT FOR THE DEVELOPMENT OF SILICON HETEROJUNCTION SOLAR CELLS
}

\author{
Miroslav Mikolášek — Michal Nemec — Jaroslav Kováč \\ - Ladislav Harmatha — Lukáš Minařík
}

\begin{abstract}
In this paper we present the utilization of capacitance and current-voltage diagnostic techniques to analyse silicon heterojunction solar cell structures properties, particularly focused on the inspection of the amorphous emitter and amorphous silicon/crystalline silicon hetero-interface. The capacitance characterization of investigated samples have revealed the need for improvement of the a-Si:H/c-Si heterointerface quality as a main direction to obtain superior output performance of heterojunction cells. In addition, current-voltage characterization emphasized importance for enhancement of the light management in the structure. The obtained results demonstrate that electrical and capacitance diagnostic techniques can represents important diagnostic tools in the process of optimization of solar cells.
\end{abstract}

K e y w or d s: solar cells, heterojunction, amorphous silicon, capacitance diagnostics, electrical characterization

\section{INTRODUCTION}

Silicon heterojunction solar cells (SHJ) are extremely appealing technology promising high conversion efficiency and low fabrication cost [1-3] in comparing to the traditional wafer based silicon solar cells. The SHJ structure consist of heterojunction between amorphous silicon and crystalline silicon and the output performances are strongly associated with the well-developed fabrication process of the heterointerface. To fully utilize the potential of used fabrication technologies there is necessary to have support of fast and reliable diagnostic techniques. In this paper, we present the utilization of capacitance and current-voltage diagnostic techniques to analyse SHJ structure properties particularly focused on the inspection of the amorphous emitter and amorphous silicon/crystalline silicon hetero-interface. The aim of this study is to demonstrate the applicability of the electrical and capacitance measurements in the development process of SHJ solar cells.

One of the most important parameters of the SHJ cell is the heterointerface quality [4]. We have used two admittance diagnostic techniques for investigation of a-Si:H/c-Si interface quality. For the first one were employed the dark capacitance and conductance measurements as a function of temperature and frequency ( $C-T-\omega$ and $G-T-\omega)$ while for the second one the measurement of the capacitance as a function of frequency at forward bias $(C-V-F)$. To reveal the heterointerface defect states density $C-T-\omega$ and $G-T-\omega$ measurements were successfully used for characterization of a-Si:H/c-Si heterojunction solar cells, since in general, the temperature and frequency dependence of the junction capacitance is sensitive to interface properties [5]. In the ex- perimentally measured temperature dependence of the capacitance usually two steps-like deviation of the capacitance accompanied with the peaks in the temperature dependence of the conductance can be observed [6]. The first one occurs in the low temperature range $(100-250 \mathrm{~K})$ and is attributed to the carrier transport in the a-Si:H layer and the second one presents at higher temperature $(>250 \mathrm{~K})$ is associated with emission of electrons and holes by the interface defect states and reflect the interface quality. Due to the high c-Si space charge capacitance background, however, the method suffers from low sensitivity.

The $C-T-\omega$ and $G-T-\omega$ methods can provide the basic information about the quality of the interface however suffer from low sensitivity. To study interface in details there is necessary to employ $C-V-F$ diagnostic technique [7] based on the measurements of diffusion capacitance at forward bias close to the open-circuit voltage under AM1.5 illumination. The detection principle of the method steams from the change of the diffusion capacitance. Diffusion capacitance is related to the rearrangement of minority carrier density, which is strongly related to the recombination process at the interface. The measured low frequency capacitance then can provide information about the recombination at the interface. Due to the applied illumination, an increased sensitivity of measured low frequency capacitance on the quality of the interface is obtained.

The capacitance analysis of samples was completed by the current-voltage $(I-V)$ measurements under illumination carried out at various temperatures. Analyzing output parameters obtained from light $I-V$ we suggest the main directions for output performance improvement of the studied samples.

* Institute of Electronics and Photonics, Faculty of Electrical Engineering and Information technology, Slovak University of Technology, Ilkovičova 3, 81219 Bratislava, Slovakia. miroslav.mikolasek@stuba.sk 

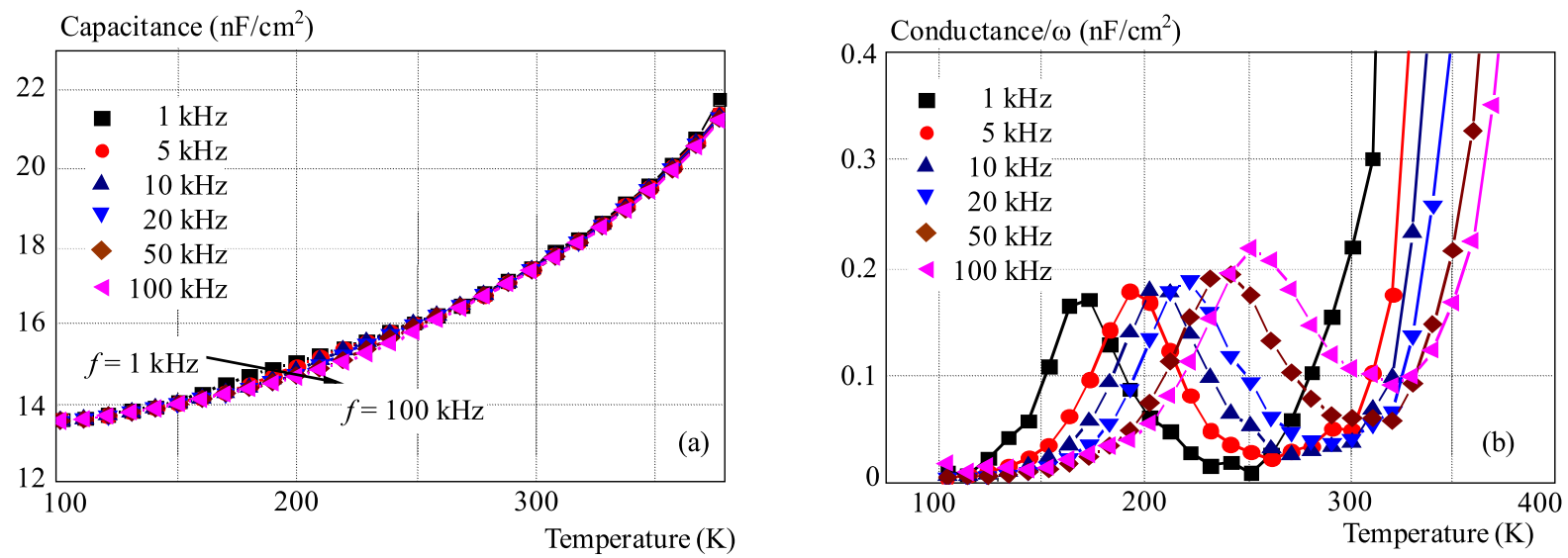

Fig. 1. Temperature and frequency dependence of capacitance and conductance measurements in the dark at $0 \mathrm{~V}$ bias

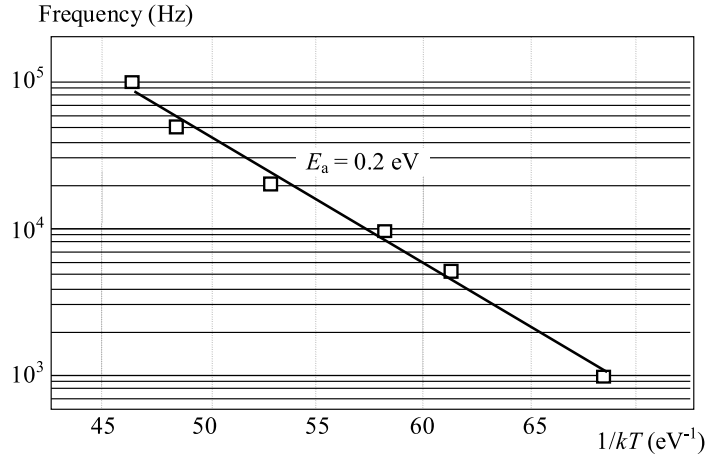

Fig. 2. Arrhenius plot constructed from the maxima of measured conductance peaks at various frequencies
For characterization of silicon heterojunction solar cells properties the following vertical sequence of layers was used: $\mathrm{p}^{+} \mathrm{Si}$ back contact/ $\mathrm{p}$-type Si substrate of thickness $500 \mu \mathrm{m} /$ intrinsic a-Si:H $10 \mathrm{~nm} / \mathrm{n}$-type a-Si:H $20 \mathrm{~nm} / \mathrm{ZnO}: \mathrm{Al} 900 \mathrm{~nm}$. Amorphous silicon layers were deposited at CNR-IMM in Catania, Italy using Inductively Coupled Plasma Chemical Vapor Deposition technique (ICP-CVD) at substrate temperature $90^{\circ} \mathrm{C}$. Prior the deposition the silicon substrates were cleaned in the diluted $\mathrm{HF}$ solution. As a gas precursor $\mathrm{SiH}_{4}, \mathrm{H}_{2}$, and $\mathrm{PH}_{3}$ was used for preparation of intrinsic and n-type doped amorphous layers, respectively. The deposition of $\mathrm{ZnO}$ :Al layer was performed by magnetron sputtering. Device geometries were then defined by photolithography followed by a-Si:H and crystalline silicon chemical and reactive ion etching [8]. The evaporation of the back full area aluminum contact with thickness $120 \mathrm{~nm}$ and capacitance and current-voltage characterization of samples was carried out at the Institute of Electronics and Photonics, Slovak University of Technology in Bratislava.

The admittance measurements were conducted using the precision LCR METER AGILENT 4284A and current-voltage $(I-V)$ measurements by Keithley 237 instrument. The solar simulator model 16S-002-300 from company SOLAR Light was used as a light source. The light measurements were done at illumination intensity $100 \mathrm{~mW} / \mathrm{cm}^{2}$ and solar spectrum AM1.5. The measurements at various temperatures were provided using the cryostat system.

The analysis of $C-V-F$ measurements we provided by simulation utilizing the AFORS-HET software. The parameter database of AFORS-HET software completed with parameters obtained from measurement was used to prepare the model of the simulated structures. The interface was described by introducing a defective interface layer with a thickness of $1 \mathrm{~nm}$ between c-Si and a-Si:H. The defect states in the defective interface layer were modeled with constant value over the whole band gap.

\section{RESULTS AND DISCUSSION}

The dark admittance measurements of silicon heterojunction solar cell structure were carried out at $0 \mathrm{~V}$ bias and frequencies 1, 5, 10, 20, 50 and $100 \mathrm{kHz}$. From the measurements the capacitance, Fig. 1(a), and the conductance over $\omega$ to better pronounce the observed peaks, Fig. 1(b), as a function of temperature and frequency $(C-T-\omega, G-T-\omega)$ were extracted. By analyzing the capacitance and conductance temperature measurements behavior a variance of the capacitance in the temperature range $150-250 \mathrm{~K}$ was observed, which is noticeable with change of the frequency. This change of the capacitance is accompanied with the peaks in the $G-T-\omega$ characteristics. The process responsible for such behavior has temperature character and therefore can be analyzed by Arrhenius plot. The activation energy obtained from the Arrhenius plot has value $E_{\mathrm{a}}=0.2 \mathrm{eV}$ (Fig. 2). The presence of the peaks in the $G-T-\omega$ characteristics at low temperature is attributed to the onset of the carrier transport or of the response of gap states at the Fermi level in the a-Si:H emitter. Therefore the activation energy of this process corresponds to the difference between the bottom of the conduction band and the Fermi level in a-Si:H, in other words doping activation energy of the emitter.

By using the simulations as was shown in [6], the presence of similar step-like increase of the capacitance at the 


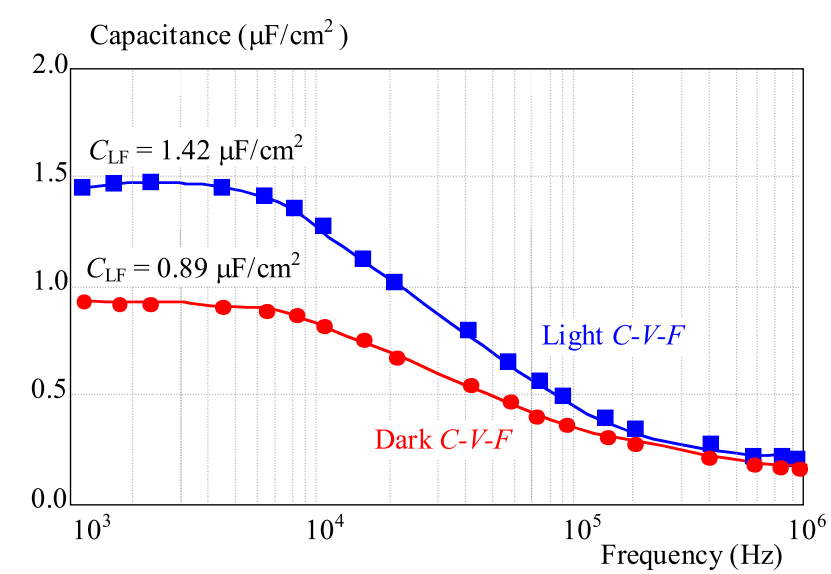

Fig. 3. Dark and light $C-V-F$ characteristics measured at forward bias $0.55 \mathrm{~V}$ and illumination $100 \mathrm{~mW} / \mathrm{cm}^{2}$

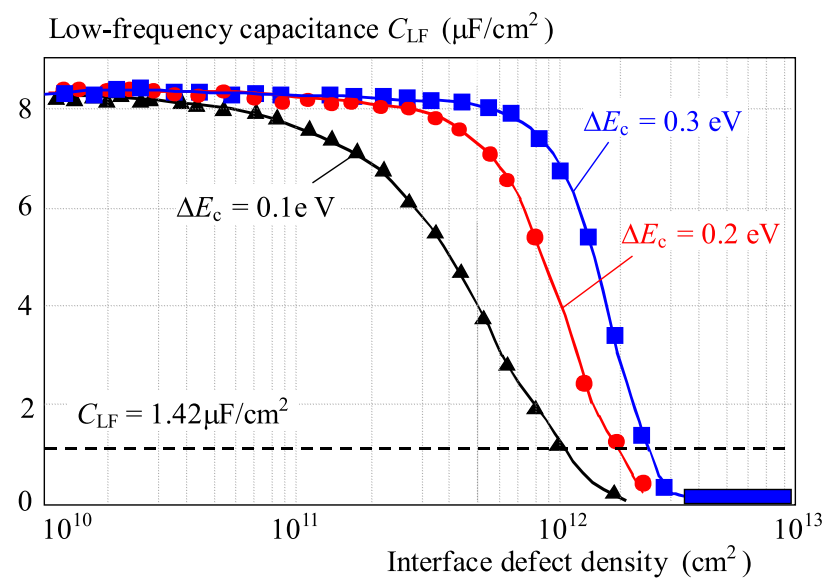

Fig. 4. Simulation of light low-frequency capacitance $(f=1 \mathrm{kHz})$ as a function of defect states density at the amorphous silicon/crystalline silicon interface at forward bias $0.55 \mathrm{~V}$ and illumination intensity $100 \mathrm{~mW} / \mathrm{cm}^{2}$

Current density $\left(\mathrm{mA} / \mathrm{cm}^{2}\right)$

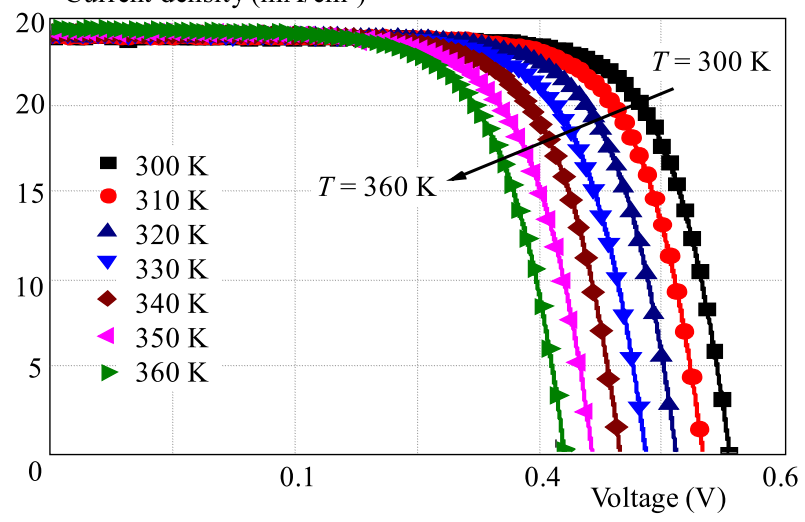

Fig. 5. Simulation of light low-frequency capacitance $(f=1 \mathrm{kHz})$ as a function of defect states density at the amorphous silicon/crystalline silicon interface at forward bias $0.55 \mathrm{~V}$ and illumination intensity $100 \mathrm{~mW} / \mathrm{cm}^{2}$

temperatures above $250 \mathrm{~K}$ can be used as a rough indication of the defect states at the heterointerface. In this case the change of the capacitance is caused by trapping and emission of charge carriers at interface states. The low sensitivity of such approach, however, constrains the minimal detectable value of defect states to $5 \times 10^{12} \mathrm{~cm}^{-2}[6]$. Since we do not observe such capacitance change in $C-T-\omega$ characteristics, we can assume defect states at the heterointerface below $5 \times 10^{12} \mathrm{~cm}^{-2}$.

The dark and light $C-V-F$ curves measured at forward bias $0.55 \mathrm{~V}$ are shown in Fig. 3. The measured capacitance represents parallel capacitance in the equivalent parallel circuit of a conductance and capacitance. Due to the forward bias measured capacitance represents diffusion capacitance and reflects concentration of minority carriers in the structure. The minority carriers concentration is directly affected by the recombination processes in the structure. While the heterojunction solar cell structure was prepared on high quality substrate and utilizes back surface field to suppress recombination at the back surface, we can assume that the main contribution of the recombination has sources at the interface. Both illuminated and dark $C-V-F$ curves exhibit saturation of the capacitance at low frequencies. Saturated capacitance has higher value for measurement carried out under illumination, which has origin in higher concentration of carriers due to the photogeneration. The measurements under illumination thus provide higher sensitivity and were further analyzed. To extract the value of the defect states at the interface we have chosen low-frequency capacitance at $1 \mathrm{kHz}\left(C_{\mathrm{LF}}\right)$ and was compared it with the simulation of parallel $C_{\mathrm{LF}}$ calculated by the program AFORS-HET. In Fig. 4 is shown the simulated curve of $C_{\mathrm{LF}}$ under illumination $100 \mathrm{~mW} / \mathrm{cm}^{2}$ as a function of defect states at the amorphous silicon/crystalline silicon interface. To assume the influence of the band mismatch at the heterojunction we have made the calculation for three values of conduction band offsets $\Delta E_{\mathrm{C}}=0.1,0.2$ and $0.3 \mathrm{eV}$. The values of $\Delta E_{\mathrm{C}}$ in the range $0.1-0.3 \mathrm{eV}$ are the most typical values of a-Si:H/c-Si heterojunction [9-11]. Based on this analysis we have estimated the defect states density at the interface in the range $D_{\text {it }} \sim 1 \times 10^{12}-2 \times 10^{12} \mathrm{~cm}^{-2}$.

Current-voltage characteristics measured under sun simulator with spectrum AM1.5 and light intensity $100 \mathrm{~mW} / \mathrm{cm}^{2}$ at various temperatures are shown in Fig. 5. Extracted output parameters open-circuit voltage $\left(V_{\mathrm{OC}}\right)$, short-circuit current $\left(J_{\mathrm{SC}}\right)$, fill factor $(F F)$ and conversion efficiency $(\eta)$ are shown in Figs. 6a and 6b. As shown in Fig. $6 a$ the strong linear dependence of the $V_{\mathrm{OC}}$ is noticeable. When approximating of such dependence with the linear curve, one can obtain the value of activation energy $E_{\mathrm{a}}$ in solar cells utilizing following equation

$$
V_{\mathrm{OC}} \approx \frac{E_{\mathrm{a}}}{q}-\frac{n_{\mathrm{id}} k T}{q} \ln \frac{J_{00}}{J_{\mathrm{SC}}}
$$

In the equation, $J_{00}$ is weekly temperature dependent current prefactor, $q$ is elementary charge, $T$ temperature and $n_{\text {id }}$ is the ideality factor. As can be seen, the activation energy is equal to the value of open-circuit voltage at the temperature $0 \mathrm{~K}$ and thus can be determined as an intersection of $V_{\mathrm{OC}}$ vs $T$ curve with the $y$-axis. The 

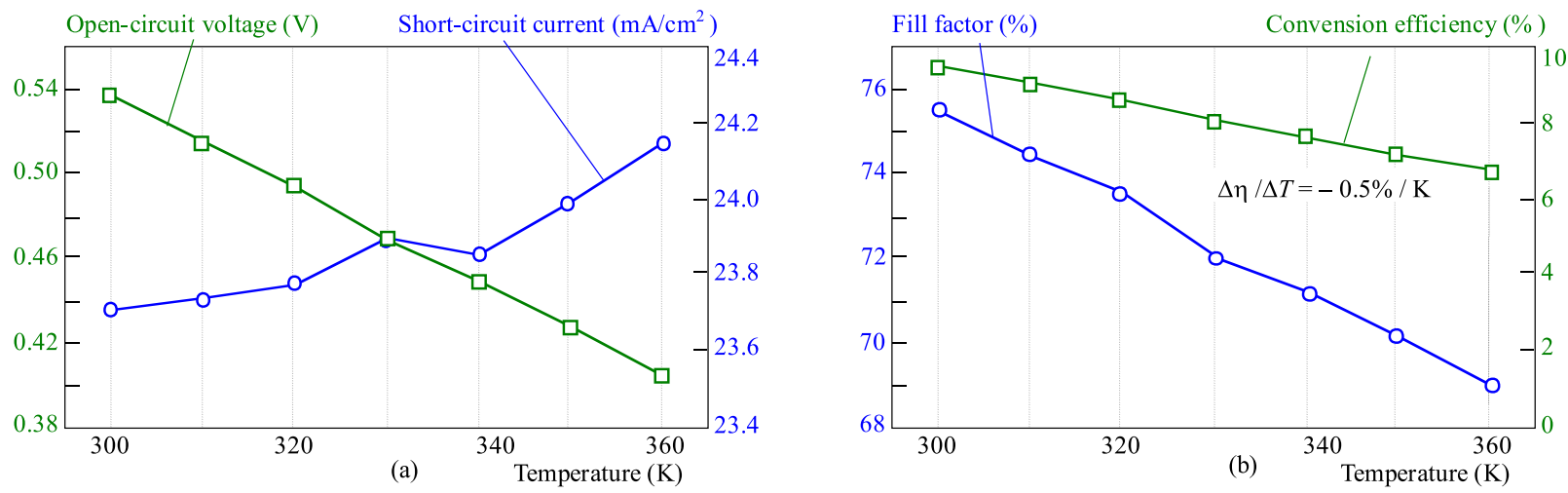

Fig. 6. Basic output parameters extracted from light $I-V$ characteristics measured in the temperature range 300-360 K, at illumination $100 \mathrm{~mW} / \mathrm{cm}^{2}$

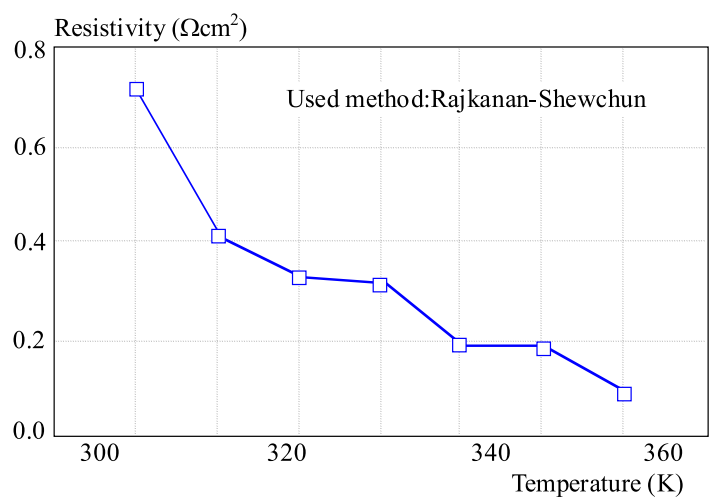

Fig. 7. Series resistance as a function of temperature

activation energy value $E_{a}=1.2 \mathrm{eV}$ was determined for the investigated sample.

From the output parameters characteristics is observable the decrease of $V_{\mathrm{OC}}$ and $F F$ with increasing temperature. This results to the overall decrease of the $\eta$ with relative temperature coefficient $-0.50 \% / \mathrm{K}$.

The series resistance as a function of the temperature of measured sample is shown in Fig. 7. The resistivity was obtained by the Rajkanan-Shewchunt method [12], which is based on the measurement of dark and light $I-V$ characteristics. The series resistance is then calculated as

$$
R_{\mathrm{S}}=\frac{V_{\mathrm{D}}-V_{\mathrm{OC}}}{J_{\mathrm{SC}}}
$$

where $V_{\mathrm{D}}$ is the voltage obtained from the forward dark $I-V$ at $J=J_{\mathrm{SC}}$. The Rajkanan-Shewchunt method belong to the one of the most accurate [12]. Measured were low series resistance with value below $1 \Omega \mathrm{cm}^{2}$ in the whole temperature range $300-360 \mathrm{~K}$.

The performed analysis allows us to gain deep insight on the silicon heterojunction solar cell structure that exhibits limitation in the output performance especially due to low $V_{\mathrm{OC}}$ and $J_{\mathrm{SC}}$ values. The capacitance analysis has revealed that the defect states at the heterointerface have value $D_{\text {it }} \sim 1 \times 10^{12}-2 \times 10^{12} \mathrm{~cm}^{-2}$. To improve the performance of prepared SHJ solar cell and to attain higher $V_{\mathrm{OC}}$ it is necessary to improve the quality of the amorphous silicon/crystalline silicon interface and achieve $D_{\text {it }}<10^{12} \mathrm{~cm}^{2}$.

For improvement of $J_{\mathrm{SC}}$ is required to focus on the absorption and light management in the structure. From the layer composition of the structure, we can assume that the main sources of the absorption is thick $\mathrm{ZnO}: \mathrm{Al}$ layer and amorphous emitter. Improvement can be achieved by replacing the amorphous silicon emitter with the amorphous silicon with incorporated carbon (a-SiC:H) or oxygen $(\mathrm{a}-\mathrm{SiO}: \mathrm{H})$. Both materials have higher band gap compared to amorphous silicon and thus lower absorption [13]. Further decrease of the absorption can be achieved by decreasing the thickness of the intrinsic amorphous silicon passivation layer. Optimization of the light management by texturing of the silicon substrate, as another way of increasing $J_{\mathrm{SC}}$, will gain increased importance mainly with the decreasing of the silicon substrate thickness.

Using the admittance spectroscopy $C-T-\omega$ and $G-T-\omega$ we have measured the distance between Fermi level and conduction band in the amorphous emitter. The value of the activation energy $0.2 \mathrm{eV}$ indicates effective doping of the amorphous silicon prepared by ICP-CVD deposition technology.

From the light $I-V$ characterization at various temperatures the temperature coefficient of efficiency was evaluated as equal to $0.50 \% / \mathrm{K}$. This is significantly higher value compared to $0.2-0.3 \% / \mathrm{K}$, which is typical for SHJ solar cells [14]. The temperature coefficient of the efficiency is directly related with the value of the opencircuit voltage as shown in [14]. Therefore, we can attribute such high drop of the efficiency upon the temperature with low value of the $V_{\mathrm{OC}}$ of studied sample. By optimization of the $V_{\mathrm{OC}}$ we can expect the decreases of this temperature coefficient. The value of determined activation energy $E_{\mathrm{a}}=1.2 \mathrm{eV}$ is close to the crystalline silicon band gap, which indicates the recombination in the neutral part of the crystalline substrate as a dominant mechanism of the carrier transport in the structure. The low serial resistance of ICP-CVD heterojunction sample predicts good performance even at high illumination intensities, which can be important in concentrator systems. 


\section{CONCLUSION}

In this paper we demonstrated the applicability of capacitance and current-voltage measurements for analyzing silicon heterojunction solar cells. The analysis was focused on the most important parameters of SHJ structure including characterization and simulation of heterointerface and emitter layers. As a main source of the low output performance of studied silicon heterojunction solar cell was detected the recombination at the heterointerface and high absorption in the $\mathrm{ZnO}: \mathrm{Al}$ and amorphous emitter.

\section{Acknowledgement}

The work has been conducted with the support of the projects VEGA $1 / 0439 / 13$ and $1 / 0377 / 13$. The authors thanks to CNR-IMM and STMicroelectronics in Catania, Italy for samples preparation in the frame of ERG project.

\section{REFERENCES}

[1] TOHODA, S.-FUJISHIMA, D.-YANO, A.-OGANE, A.MATSUYAMA, K.-NAKAMURA, Y.-TOKUOKA, N.KANNO, H.-KINOSHITA, T.-SAKATA, H.-TAGUCHI, M.-MARUYAMA, E. : Future Directions for Higher-Efficiency HIT Solar Cells using a Thin Silicon Wafer, Journal of Non Crystalline-Solids 358 No. 17 (2012), 2219-2222.

[2] MIKOLÁŠEK, M.-NEMEC, M.-KOVÁČ, J.et al : Electrical Characterisation of a-Si:H(n)/c-Si(p) Heterostructures for Solar Cell Applications, In Proceedings of ASDAM'12 Conference, Smolenice, Slovakia, 2012, pp. 115-118.

[3] De WOLF, S.-DEScoeudReS, A.-HOLMAN, Z. C.-BALLIF, C. : High-Efficiency Silicon Heterojunction Solar Cells: A Review, Green 2 (2012), 7-24.

[4] SCHMIDT, M.-KORTE, L.-LAADES, A.-STANGL, R.SCHUBERT, C.-ANGERMANN, H.-CONRAD, E.-MAYDELL, K.: Physical Aspects of a-Si:H/c-Si Hetero-Junction Solar Cells, Thin Solid Films 515 No. 19 (July 2007), 7475-7480.

[5] GUDOVSKIKH, A. S.-KLEIDER, J.-DAMON-LACOSTE, J.-ROCA i CABARROCAS, P.-VESCHETTI, Y.-MULLER, J.-RIBEYRON, P.-ROLLAND, E.: Interface Properties of a-Si:H/c-Si Heterojunction Solar Cells from Admittance Spectroscopy, Thin Solid Films 511-512 (July 2006), 385-389.

[6] GUdovskikH, A. S.-KLEIDER, J. P.-TERUKOV, E. I. : Characterization of an a-Si:H/c-Si Interface by Admittance Spectroscopy, Semiconductors, 39 No. 8 (Aug 2005), 904-909.

[7] GUdovskikH, A. S.-KLEIDER, J. P.: Capacitance Spectroscopy of Amorphous/Crystalline Silicon Heterojunction Solar Cells at Forward Bias and under Illumination, Appl. Phys. Lett. 90 No. 3 (2007), 034104.

[8] MIKOLÁŠEK, M.-NEMEC, M.—KOVÁČ, J.-VINCZE, A. FOTI, M.-GERARDI, C.-MANNINO, G.-VALENTI, L.LOMBARDO, S. : Impact of Annealing on the Amorphous Silicon/Crystalline Silicon Heterojunction Solar Cellsinbook $28^{\text {th }}$ European Photovoltaic Solar Energy Conference and Exhibition: Proceedings, Paris, France, 30.9-4.10 2013, Mnchen: WIP.

[9] SCHMidT, M.-KORTE, L.-LAADES, A.-STANGL, R.SCHUBERT, C.-ANGERMANN, H.-CONRAD, E.-MAYDELL, K.: Physical Aspects of a-Si:H/c-Si Hetero-Junction Solar Cells, Thin Solid Films 515 No. 19 (July 2007), 7475-7480.

[10] KLEIDER, J. P.-GUDOVSKIKH, A. S.-ROCA i -CABARROCAS, P.: Determination of the Conduction Band Offset between Hydrogenated Amorphous Silicon and Crystalline Silicon from Surface Inversion Layer Conductance Measurements, Applied Physics Letters 92 No. 16 (2008), 162101.

[11] SEBASTIANI, M.-Di GASPARE, L.-CAPELLINI, G.-BITTENCOURT, C.-EVANGELISTI, F.: Low Energy Yield Spectroscopy as a Novel Technique for Determining Band Offsets: Application to the c-Si(100)/a-Si:H Heterostructure, Phys. Rev. Lett. 75 (1995), 3352-3355.

12] RAJKANAN, K.-SHEWCHUN, J. : A Better Approach to the Evaluation of the Series Resistance of Solar Cells, Solid-State Electron. 22 (Feb 1979), 193-197.

[13] DING, K.-AEBERHARD, U.-FINGER, F.-RAU, U.: Silicon Heterojunction Solar Cell with Amorphous Silicon Oxide Buffer and Microcrystalline Silicon Oxide Contact Layers, Phys. status solidi - Rapid Res. Lett. 6 No. 5 (May 2012), 193-195.

[14] MISHIMA, T.-TAGUCHI, M.-SAKATA, H.-MARUYAMA, E. : Development Status of High-Efficiency HIT Solar Cells, Sol. Energy Mater. Sol. Cells 95 No. 1 (Jan 2011), 18-21.

15] TSUNOMURA, Y.-YOSHIMINE, Y.-TAGUCHI, M.-BABA, T.-KINOSHITA, T.-KANNO, H.-SAKATA, H.-MARUYAMA, E.-TANAKA, M. : Twenty-Two Percent Efficiency HIT Solar Celljour Solar Energy Materials and Solar Cells.

Received 6 October 2013

Miroslav Mikolášek (Ing, PhD), was born in Myjava (Slovakia), in 1983. He carried out research in the area of microfluidic circuits at the Johannes Kepler University in Linz, Austria, and based on this work he received his Master degree in electronics from the Slovak University of Technology, Bratislava, in 2007. In year 2011 he recived $\mathrm{PhD}$ degree in Electronics from the Slovak University of Technology. At present he works at the Institute of Electronics and Photonics, Slovak Technical University in Bratislava. Main interests of his research include simulation and diagnostics in the field of solar cells based on amorphous silicon.

Michal Nemec Michal Nemec (Ing) was born in Myjava (Slovakia), in 1984. He received his Master degree in electronics from the Slovak University of Technology, Bratislava, in 2009.In his research, he is focused on the diagnostics of silicon heterojunction solar cells.

Jaroslav Kováč (Prof, Ing, CSc) was born in Šafárikovo, Slovakia, in 1947. He graduated from the FEI STU, Bratislava, in 1970. Since 1971 he has been engaged in the research of optoelectronic devices technology at the Microelectronics Department of FEI STU. He received a CSc $(\mathrm{PhD})$ degree from STU Bratislava, in 1983. Since 1991 he has been the team leader of the Optoelectronic and microwave group at the Department of Electronics and Phototonics.

Ladislav Harmatha (Assoc Prof, Ing, CSc) was born in Dobšiná, Slovak Republic, in 1948. In 1971 he graduated from the Faculty of Electrical Engineering, STU Bratislava, in 1984 received the $\mathrm{PhD}$ degree and was appointed associate professor in 1996. In 1971 he joined the staff of the Department of Microelectronics, FEI STU in Bratislava, as a research worker. Since 1988 he has worked as a senior scientist in the field of semiconductor defects engineering. His research is focused on defects in semiconductor structures and their characterization by means of electrical methods. He is the author of about 60 scientific and technical papers and 26 research reports.

Lukáš Minařík (Bc) was born in Banská Bystrica, Slovakia, in 1990. He received his Bachelor degree in electronics from the Slovak University of Technology in 2012. At present he studies microelectronics at the FEI, Slovak University of Technology, Bratislava. 